\title{
Estudos culturais: as margens de um programa de pesquisa
}

\author{
Ana Carolina D. Escosteguy ${ }^{1}$ \\ PUC-RS \\ carolad@pucrs.br
}

\begin{abstract}
Resumo: Este artigo tem como objetivo mapear a existência de vários posicionamentos no interior da formação discursiva dos estudos culturais. Identifica-se uma proposta alinhada a uma teoria social crítica que toma como foco o texto midiático e seu contexto; uma outra associada a uma teoria interpretativa que se concentra nas audiências; uma terceira que se configura como uma proposta polifônica e atualmente está atenta para a problemática das identidades culturais; e uma quarta que tematiza as relações entre ciência, tecnologia e cultura, desenvolvendo-se, sobretudo, a partir do feminismo e aproximando-se da temática da cibercultura. Até o momento, são esses os distintos aportes dos estudos culturais que são aplicados a diferentes problemas-objeto, repercutindo em análises culturais da mídia.
\end{abstract}

Palavras-chave: Estudos culturais; estudos de mídia; método.

Abstract: This article aims to map the existence of several positionings within the discursive formation of the cultural studies. One identifies a proposal lined up with critical social theory that takes as focus the media text and its context; another one associated to an interpretative theory that has its focal point on the audiences; a third one that is configured as a polyphonic proposal and that is attentive to the problematic of the cultural identity; and a fourth that debates the relationship between science, technology, and culture, developing itself, mainly from the feminism and coming close to the thematic of cyberculture. Until this moment, these are the distinct contributions to the cultural studies that are applied to different objectproblems reverberating in cultural analysis of media.

Keywords: Cultural studies; media studies; method.

${ }^{1}$ Professora do Programa de Pós-graduação em Comunicação Social da FAMECOS/PUCRS; pesquisadora do CNPq. 
Este é um esforço de síntese ${ }^{2}$ que tem como objetivo mapear a existência de vários posicionamentos no interior da formação discursiva dos estudos culturais (HALL, 2003: 200). Tais posições revelam-se na adoção de distintos discursos sobre o método que, por sua vez, aplicam-se a diferentes problemas-objeto no amplo espectro dos estudos de mídia. Portanto, quando se tem em vista a contribuição metodológica dos estudos culturais para o campo da comunicação, identifica-se uma proposta alinhada a uma teoria social crítica que toma como foco central o texto midiático e seu contexto; uma outra associada a uma teoria interpretativa que se concentra nas audiências; uma terceira que se configura como uma proposta polifônica de elementos de distintas tradições intelectuais que está atenta para a problemática das identidades culturais e uma quarta, que tematiza as relações entre ciência, tecnologia e cultura, desenvolvendo-se, sobretudo, a partir do feminismo e aproximando-se ao problema-objeto da cibercultura. Tal heterogeneidade é na maioria das vezes a motivação que funda a crítica aos estudos culturais. Contudo, neste momento, sem desconhecer esse problema, apenas destaco os distintos aportes que se encontram em evidência nos estudos culturais e repercutem em análises culturais da mídia.

No primeiro posicionamento localizo a proposta de Douglas Kellner que, em termos de tradição metodológica ${ }^{3}$, exemplifica a existência de uma variante social-crítica no âmbito dos estudos culturais. Como princípios norteadores de sua proposição, o autor tenta superar teorias unilaterais como a da manipulação ou controle social, exigindo que os textos midiáticos sejam analisados como expressão de várias vozes. De modo, ainda, abrangente, propõe que o estudo da cultura deve estar articulado a uma teoria social, pois é preciso compreender as estruturas e a dinâmica da sociedade para entender a esfera cultural.

\footnotetext{
${ }^{2}$ Aqui, sumarizo a bibliografia utilizada no curso Estudos Culturais e Comunicação, nas suas diversas versões, ministrado no curso de Pós-graduação em Comunicação Social da FAMECOS/PUCRS.

3 Assumo tal termo no lugar de tradição epistemológica, dado o nível de problematização adotado. Sobre as distintas tradições, sigo orientação de AGGER (1998) e GUNTER (2000).
} 
O próprio autor insiste em situar sua proposição no âmbito dos estudos culturais críticos. As razões para isso podem ser vistas na sua referência às proposições originais da Escola de Frankfurt, tradição que inaugura os estudos críticos da cultura. No entanto, o autor pretende evitar o caráter ensaístico dos teóricos críticos, reivindicando uma análise de fenômenos concretos. Explorando um veio um tanto obliterado na abordagem crítica, insiste que a análise cultural não pode limitar-se à crítica da ideologia dominante, mas também deve abranger os momentos emancipatórios (ver RÜDIGER, 2004: 250-253 e RÜDIGER, 2002: 83-84, 118-121).

De toda forma, reconhece a importância da teoria para elucidar o mundo social e, em especial, da teoria crítica que estabelece nexos entre partes isoladas da sociedade, mostrando de que modo a economia se insere nos processos da cultura da mídia e estrutura o tipo de texto que é produzido nas indústrias culturais. Por essa razão, tal perspectiva proporciona a moldura para situar seu programa de pesquisa, pois localiza os objetos de estudo no quadro do desenvolvimento do capitalismo. No entanto, também, aponta limites importantes na abordagem crítica. Entre eles, a dicotomia entre cultura superior e inferior, a limitação dos momentos críticos e emancipatórios à cultura superior e o enfraquecimento da distinção entre codificação e decodificação.

A partir desse posicionamento, propõe uma pesquisa que comporte a contribuição da economia política da mídia, assim como das vertentes que dão conta dos processos de produção da cultura; da investigação empírica e histórica da construção da indústria da mídia e sua relação com outras instituições; dos estudos de recepção e, finalmente, da incorporação de novas teorias para atualização da teoria crítica.

Nessa última direção, a inclusão proposta diz respeito aos marcadores de identidade social como gênero, raça, etnia, classe, preferências sexuais, nacionalidade, entre outros, os quais retiram peso da teorização sobre a 
mercantilização da cultura. Além disso, a preocupação em compreender a cultura da mídia como um terreno de disputas, contradições e conflitos sociais, premissa assumida pelos estudos culturais britânicos, tensiona o pressuposto de que a indústria cultural condiciona esses mesmos conflitos.

Da tradição teórica dos estudos culturais britânicos sugere, ainda, resgatar a idéia de que a cultura midiática cria tanto formas de dominação ideológica que reiteram as relações de poder vigentes quanto fornece material para construção da resistência, por isso, a cultura é entendida como uma prática que implica participação dos sujeitos. Contudo, ao mesmo tempo que reconhece a produtividade de tais pressupostos, não deixa de apontar algumas de suas deficiências. Entre elas: a tendência a ignorar formas da cultura superior; a subvalorização do modo como os textos são produzidos; os exageros na valorização da atividade dos sujeitos, deixando de lado o modo como o público é produzido tanto pelas relações sociais quanto pela própria cultura e, finalmente, o fetichismo da resistência.

Articuladas às premissas já indicadas a partir da teoria crítica e dos estudos culturais britânicos, Kellner procura descrever as condições que dão origem à resistência ou ao prazer e aos seus efeitos, mas discriminando a resistência que desafia as estruturas existentes de poder daquelas que não alteram essa relação. Sua intenção é situar os textos dentro do sistema de produção, distribuição e consumo, atentando para o poder que os textos midiáticos exercem sobre os públicos, ou seja, a cultura da mídia, também, posiciona esses mesmos consumidores.

Enfim, a crítica cultural proposta por Kellner, chamada de estudo crítico, multicultural e multiperspectívico da mídia, configura-se como uma teoria social crítica dado as bases teóricas onde se fundamenta. Pressupõe uma ponte dialética entre estrutura e agência, pois a cultura é vista como prática, sempre situada num espaço social e econômico complexo onde tal atividade é condicionada. A intenção é revelar a reprodução da estrutura 
social, porém não se associa à idéia de que a sociedade é governada por leis imutáveis. Ao contrário, insiste no poder da ação pessoal e coletiva para transformar a sociedade. Sendo assim, a cultura, embora constituída por uma estrutura social particular, não é estudada como mero reflexo dessa última. Por tudo isso, identifica-se em tal proposta um cunho político já que deve estar situada no contexto de debates e embates sociais em curso no momento de sua realização. E somente será esclarecedora desde que situe o texto em análise em seu contexto histórico.

No entanto, em termos de problemas-objeto, prefiro compreender seu programa de pesquisa como uma análise cultural centrada no texto e contexto, apesar de sua insistência em reivindicar um estudo que abarque a produção, a circulação e o consumo, ou seja, um olhar integral do processo comunicativo. Geralmente, as análises apresentadas em seus trabalhos destacam um determinado produto cultural, embora este possa estar articulado com outros, em circulação num momento histórico específico. E o consumo é apenas parcialmente problematizado.

O segundo posicionamento é expresso na pesquisa das audiências associando-se na maioria das vezes, em termos de tradição metodológica, a uma postura interpretativa na medida em que dá forte atenção à ação social. Decorrência disso, essa vertente está fixada nos sentidos que as pessoas dão às suas próprias ações no cotidiano o que a leva a entender que a sociedade é formada por esses sentidos que os seres humanos lhe atribuem. Portanto, a ação social fica reduzida às intenções dos sujeitos, desprezando-se a estrutura material que restringe sua capacidade de ação. A pesquisa interpretativa trata tais narrativas como tendo um valor verdadeiro, desprezando que os sentidos construídos pelos sujeitos são mediados pela consciência e condicionados pela estruturação mais geral da sociedade.

Contudo, não é toda a trajetória de pesquisa das audiências que aderiu a essa base teórica, por isso, vale a pena reconstituir sumariamente esse itinerário. De modo esquemático, é possível anotar três momentos no desenvolvimento dessa vertente no âmbito dos estudos culturais. Nos anos 80, 
o primeiro deles concentrou sua atenção na relação texto/receptor. Embora o foco estivesse nas leituras possíveis do texto em análise, tratava-se de discutir o poder do texto versus a autonomia da leitura. É exemplar a esse respeito o estudo chamado The Nationwide Audience (1980), de David Morley4, onde ainda é o texto o motivador da pesquisa. Selecionando um programa televisivo de caráter misto (informativo e de variedades) que havia sido analisado anteriormente (1978), o autor investiga sua recepção a partir de grupos de discussão, armados principalmente através da atividade profissional e do nível educacional, que assistiram episódios gravados do mesmo. Através dessa estratégia, Morley conclui que os receptores não aceitam, obrigatoriamente, a leitura dominante5; existem discrepâncias de leituras entre grupos da mesma classe social ${ }^{6}$, bem como semelhanças entre grupos de posição social distinta7, portanto, as leituras não são diretamente determinadas pela condição econômica e de classe; a articulação da posição social (renda, trabalho e nível educacional) com outra posição - ou mais de uma - produz leituras específicas; os encontros entre texto/receptor estabelecem uma multiplicidade de relações nas circunstâncias de sua combinação. Além disso, no momento do encontro com o texto, outros discursos, trazidos à tona pelo sujeito, entram em operação. São estes outros discursos que, também, definem alguns dos termos em que um texto particular é apreciado. Mais tarde, Morley ${ }^{8}$ reconhece que deu demasiada atenção ao aspecto da classe social, assim como vê na sua pesquisa uma ausência das determinações do contexto sobre a(s) leitura(s). A

\footnotetext{
4 Ver, por exemplo, para mais informações JANCOVICH, Mark.David Morley, Los Estudios de 'Nationwide'. In: BARKER, Martin e BEEZER, Anne. Introducción a los estudios culturales. Barcelona: Casa Editorial Bosch, 1994.

5 É importante lembrar que essa pesquisa toma o modelo da codificação e decodificação de Stuart Hall como parâmetro, daí a indicação de leitura dominante, oposicionista e negociada. ${ }^{6}$ Por exemplo, os comerciários assumiam uma leitura oposicionista, mas os operários, uma leitura dominante. Ver, em português, para maior detalhamento MASCARELLO, Fernando. Os estudos culturais e a espectatorialidade cinematográfica: uma abordagem relativista. 189f. Tese de Doutoramento, Ciências da Comunicação. ECA/USP. São Paulo. 2004, p. 41-47.

7 Operários e gerentes de banco apresentaram, em alguns casos, uma leitura dominante. 8 Ver, por exemplo, MORLEY, David. The Nationwide audience: a critical postscript. Screen Education, v. 39, 1981.
} 
partir daí, desenha a seqüência do projeto: desenvolver uma etnografia da audiência.

Ainda como exemplo desse primeiro momento está a pesquisa de Ien Ang, Watching Dallas (1982), que escolhe um texto ficcional, o seriado Dallas, para realizar tanto uma análise do mesmo como de 42 cartas obtidas após publicar um pequeno anúncio em uma revista feminina holandesa, pedindo que lhe escrevessem dando opiniões sobre o programa. Os resultados dessa inusitada combinação metodológica revelaram que o prazer proporcionado pelo seriado relacionava-se com questões em torno do "realismo", embora este fosse entendido de modo diferente entre as fãs do seriado e aquelas que o criticam. Assim, o "realismo emocional" configura-se como fator determinante para o sucesso do programa entre as fãs de Dallas. Entretanto, a autora não deixou de observar que a série era, também, prazerosa por suas qualidades escapistas 9 .

Em síntese, neste estágio, a análise textual (aqui entendida como aquela que pretende dar conta dos sentidos propostos no próprio texto em estudo) estabelece parâmetros para a pesquisa e os sujeitos-receptores são investigados através do que falam e/ou escrevem, surgindo um crescente interesse nas suas interpretações.

Insisto na existência de um momento de transição entre o primeiro estágio e a abertura da pesquisa de cunho interpretativo. Este é ilustrado pelo trabalho de Janice Radway, Reading the Romance (1984) onde se observa a análise do texto e do ato da leitura que ocorre no cotidiano. O objeto é o livro de ficção romântica ${ }^{10}$, mas a autora dá também atenção ao mercado editorial, bem como aos próprios textos e suas leitoras. Mediante uma metodologia

\footnotetext{
9 Ver para mais detalhes EMMANUEL, Susan. Ien ang, Mirando Dallas. In: BARKER, Martin e BEEZER, Anne (orgs.) Introducción a los estudios culturales. Barcelona: Casa Editorial Bosch, 1994; ESCOSTEGUY, Ana Carolina e GRAVINO,Bárbara. Watching Dallas: uma contribuição aos estudos de recepção. Comunicação \& Informação, Universidade de Goiás, n 2, 2004; e MASCARELLO (2004: 51-53).

10 Ver, também, PURDIE, Susan. Leyendo el Romance. In: BARKER, Martin e BEEZER, Anne. Introducción a los estudios culturales. Barcelona: Casa Editorial Bosch, 1994; MASCARELLO (2004: 49-51).
} 
variada - grupos de discussão, questionários e entrevistas, Radway conclui que as interpretações das leitoras eram discrepantes de sua análise desse gênero narrativo, pois as mulheres-informantes respondiam perguntas sobre as histórias de amor falando do que a própria leitura proporcionava.

Foi a partir desse dado que a autora reforça sua atenção para a significação do ato da leitura que, segundo a investigação realizada, passa a ter um sentido especial dentro da estrutura da família patriarcal. A atividade de leitura nega a presença da mulher num contexto associado a responsabilidades pesadas, pois ler passa a significar espaço livre, liberação de tarefas, ato de independência, por isso, oferece prazer e pode ter tanto um uso desafiador como, às vezes, implicar em culpa. Desse modo, embora os romances funcionem como agentes de manutenção do sistema de relações vigente, o escapismo que proporcionam passa a ser uma prática de resistência política no contexto doméstico. Em relação ao prazer, a autora conclui que é resultado de uma interação entre atributos textuais e situações contextuais.

No final dos anos 8o, observa-se, contudo, que o desenvolvimento da pesquisa sobre as audiências manifesta-se muito mais centrado no receptor e no seu contexto. Assim, o texto deixa de ser um princípio estruturante na produção de sentido e a investigação passa a concentrar-se muito mais na compreensão das determinações contextuais da recepção. O interesse está centrado nos processos sociais onde se situa a recepção e, em especial, no contexto doméstico, entendido como marco onde se realizam as leituras dos produtos culturais.

Dentro dessa linha de investigação, pode-se indicar como um exemplo Family Television (1986), também de David Morley. Nesse estudo, o autor compreende a família como instituição mediadora do poder da mídia, sendo que as relações de poder aí reveladas configuram-se como princípio estrutural da recepção televisiva. Além disso, assume destaque a categoria gênero (feminino/masculino), tendo sido explorada na diferenciação de hábitos, preferências, atenção, enfim, como outro princípio estruturador da recepção televisiva no contexto doméstico. 
É, fundamentalmente, no desenvolvimento dessa vertente de pesquisa que a abordagem interpretativa se consolida, dado que procura construir conhecimento a partir da experiência dos sujeitos, entendendo que a vida social está baseada em interações sociais e sistemas de sentido socialmente construídos. No caso, os sujeitos/receptores possuem um entendimento de sua relação com a mídia e o que extraem dela, portanto, constroem um senso de realidade internamente vivenciado. Por sua vez, é esse sentido subjetivo da realidade, relatado pelos receptores/informantes da pesquisa, que explica a problemática da recepção.

Embora essa pesquisa social empírica contribua para revelar a complexidade do processo comunicativo e a participação de sujeitos na sua constituição, bem como para dar acesso à vida cotidiana, tende a sobrevalorizar mais a descrição do que a análise da vida social e a encarar o receptor como um indivíduo transparentemente autoconsciente de suas escolhas e posicionamentos, na maioria das vezes autônomo e livre frente aos condicionantes estruturais e daqueles que provém da própria indústria cultural, ou seja, os interesses das instituições midiáticas. Conseqüentemente, desconsidera a instância textual e seus limites. Enfim, as respostas das audiências não podem ser tomadas como "verdades", pois os sujeitos estão imersos num sistema social e seus atos de fala estão inscritos no interior de formações sociais.

O terceiro posicionamento é bem mais difícil de ser situado em uma tradição metodológica, assim como localizado em um problema-objeto. Proponho, então, pensá-lo como uma armação polifônica de variadas abordagens onde não há o privilégio de uma única lógica teórica sobre outras. Aqui, localizo a produção intelectual de Stuart Hall, em especial aquela que passa a circular a partir de meados dos anos 80. Estabeleço esse período porque considero que o itinerário anterior está mais claramente localizado nas discussões em torno da ideologia, inclusive da mídia, da centralidade da classe social e da hegemonia (ver ESCOSTEGUY, 2001: 59-138 e ESCOSTEGUY, 2003), embora já evidenciasse o tensionamento entre as contribuições de A. Gramsci e L. Althusser. A tentativa de articular essas duas reflexões revela que, teoricamente, de forma alguma, há uma síntese homogênea e coerente. 
Ao contrário, é nítida a coexistência de tradições intelectuais díspares, apesar de afiliadas ao marxismo, mas cada uma não se anula na outra ${ }^{11}$.

No que interessa, neste momento, observar, concentramo-nos na reconfiguração do debate sobre a problemática das identidades, instigada pelo cenário contemporâneo, chamado nos termos de Hall (1998), de Novos Tempos. Contudo, gostaria de enfatizar que a questão da identidade não é nova no campo dos estudos culturais. Ela emerge quando a questão da raça, um pouco mais tarde problematizada como etnicidade, entra para a agenda dos estudos culturais. Mas é somente a partir da segunda metade dos anos 80 que Hall passa a teorizar, de modo mais sistemático, sobre o tema ${ }^{12}$.

Não considero pertinente recuperar tal reflexão o que já foi feito em outro lugar (ESCOSTEGUY, 2001 e 2003), por isso, esquematicamente, associo sua contribuição à problemática das identidades a uma linhagem nãoessencialista. As identidades culturais são posicionamentos cambiantes e instáveis, construídos pelos discursos em circulação em uma determinada conjuntura, que, por sua vez, constituem a cultura e a história. Portanto, não são essências e suas origens são híbridas ${ }^{13}$.

Do ponto de vista teórico, comparado com o que foi dito sobre o período anterior, há aqui um acirramento na mistura de variadas fontes - Grasmci, Laclau,

\footnotetext{
${ }^{11}$ Esta posição é corroborada por Rojek (2003) e Procter (2004).

12 Em itinerário já delineado tomo como marcos da reflexão de Hall os textos "A relevância de Gramsci para o estudo da raça e da etnia" (1986) e "Minimal selves"(1987) onde o tom autobiográfico deste último permite ao autor reconhecer-se como migrante e negro, mas também observa a necessidade de incorporar a especificidade histórica, aí incluídas as características nacionais e regionais das conjunturas vividas.

13 É claro que tal reflexão tem um caráter problemático, pois não é possível deixar para trás as conseqüências políticas da fragmentação ou pluralidade das identidades, bem como da diferença, até mesmo porque o próprio Hall pensa tal questão no âmbito da agência e da política, isto é, de uma política emancipatória. Dois dos problemas mais aparentes estão relacionados ao "direito à diferença" que, em última instância, envolve a rejeição do homem universal, da igualdade humana genérica onde se abstraem as particularidades e que, num determinado momento histórico, foi uma conquista e o outro, trata da reivindicação de que tais diferenças são culturais, porém, na realidade, muitas delas são diferenças inscritas no corpo, em suma, diferenças sensíveis ou naturais (por exemplo, cor de pele, deficiência física, idade do corpo, traços do rosto, textura do cabelo). Portanto, o risco é desenvolver uma celebração das singularidades de grupos e isto ser traduzido em afirmações essencialistas (ver PIERUCCI, Antonio Flávio. Ciladas da diferença. São Paulo: Editora 34, 1999)
} 
Foucault, Lacan, Derrida, Bhabha, entre outros. Este procedimento, para uns, pode estar indicando uma adesão à modismos - por exemplo, no que diz respeito ao pósestruturalismo, à desconstrução e à teoria pós-colonial, porém, para outros, revela a abertura de Hall para novas teorias e novos questionamentos mas, principalmente, ruptura com concepções fixas e dicotômicas. Enfim, desde o início de sua trajetória intelectual, Hall recusa-se a ficar confinado a uma tradição intelectual ou escola de pensamento, portanto, é contrário a defesa de linguagens puras. É claro que isto é motivo para severas críticas.

A ordenação apresentada dos distintos aportes não é de todo despropositada, embora não exista nem seja necessária uma cronologia precisa da constituição de cada um deles. De toda forma, o quarto posicionamento que provém dos vínculos entre feminismo e estudos culturais, estabelece conexões com o desenvolvimento da pesquisa das audiências, bem como com a reflexão sobre as identidades culturais. Nesse sentido, é importante apontar uma concomitância entre a entrada em cena das questões em torno da raça e do gênero nos estudos culturais, pelo menos dentro do contexto anglo-saxão, constituintes, por sua vez, da problemática das identidades. Contudo, os resultados gerados por esses dois eixos de estudos são diferenciados. Um dos exemplos é o desenvolvimento de um interesse pela produção de conhecimentos científicos e culturais sobre as tecnologias.

Nesse sentido, o feminismo deu guarida a um debate sobre ciência e tecnologia dentro do ambiente criado pelos estudos culturais dado que uma das principais características que distinguem tal área de um estudo disciplinar tradicional é seu reconhecimento da incrustação cultural da produção do conhecimento. Assim, dentro desse escopo, sua primeira intervenção foi demarcar uma crítica ao essencialismo e desenvolver uma linha de atuação que abarcasse a existência de experiências e diferenças de gênero ${ }^{14}$.

\footnotetext{
14 Embora não haja espaço para reconstituir historicamente essa reflexão, é preciso observar que, em especial nos anos 70/80, esta desembocou numa homogeneização da identidade das mulheres. Ou seja, foi produzido um essencialismo às avessas.
} 
Em termos de problema-objeto, além das conexões já referidas, podese destacar uma atenção singular à cibercultura através da contribuição do ciberfeminismo. Do mesmo modo que o feminismo, este não comporta uma única definição, mas genericamente se constitui como uma ruptura com a estrutura patriarcal de pensar a tecnologia como um espaço masculino e que aliena a mulher, investigando narrativas de dominação e controle que envolvem a tecnocultura, bem como identificando no ciberespaço e nas próprias tecnologias, ambiente e instrumentos para a constituição de outras figuras que não encarnem a separação hierárquica entre homem/mulher, cultura/natureza, sujeito/objeto, entre outras ${ }^{15}$.

\section{À moda de conclusão}

A partir do mapeamento sumário desses diversos influxos dos estudos culturais, considero apropriado refletir sobre o que tais estímulos estão provocando no campo acadêmico brasileiro da comunicação. É claro que, ainda, podem surgir outros mais, na medida em que aumente a circulação e incorporação na pesquisa de fontes bibliográficas associadas a esses mesmos aportes teórico-metodológicos. Mesmo assim, já é possível notar alguns desafios que se não são conseqüência direta dos mesmos, pelo menos colaboram para configurar um outro cenário.

O primeiro aspecto a ser destacado trata da problematização de um entendimento de comunicação como um fenômeno ou evento centrado nas próprias tecnologias de comunicação. Isto é, a pesquisa brasileira em comunicação tem privilegiado como objeto de estudo os meios como instituições midiáticas, as formas simbólicas produzidas e veiculadas por essas tecnologias de comunicação e, em menor proporção, as audiências. Depreende-se daí um enfoque fragmentado e esquemático do processo comunicativo e, por sua vez, da comunicação em si mesma.

\footnotetext{
15 Nesse sentido, destaca-se a contribuição de Donna Haraway que utiliza a figura do ciborgue , um híbrido entre máquina e organismo, para constituir tal figuração, e a de Rosi Braidotti sobre os cibercorpos. Ver HARAWAY, Donna. Manifesto ciborgue: ciência, tecnologia e feminismo-socialista no final do século XX. In: TADEU, Tomás (org.). Antropologia do ciborgue - as vertigens do pós-humano. Belo Horizonte: Autêntica, 2000, p. 37-129; BRAIDOTTI, Rosi. Cyberfeminism with a difference. In: JONES, Amelia (org.). The feminism and visual culture reader. Londres: Routledge, 2003, p. 531-533.
} 
Do meu ponto de vista, os estudos culturais contribuem para revisar o próprio sentido de comunicação, considerando-a como um processo sócio-cultural básico onde se destaca a ação de todos os sujeitos envolvidos na produção de sentido. Mais do que estudar as tecnologias de comunicação em termos instrumentais, passamos a compreender a comunicação como constitutiva de práticas sociais, portanto, da estruturação da sociedade. Reconheço que nessa acepção a amplitude do olhar é potencializada ao máximo, por isso, o recorte que cabe ao campo é investigar as práticas sócio-culturais mediadas pelas tecnologias de comunicação.

Pessoalmente, insisto em que uma das possibilidades para enfrentar a excessiva divisão dos estudos de comunicação - por exemplo, viabilizada na preocupação delimitada nos produtos midiáticos ou nos meios -, é tomar modelos analíticos que contemplem o processo comunicativo como um circuito onde se observa a articulação entre momentos distintos, embora relacionados e dependentes uns dos outros. Para tal, parece-me bastante inspirador a formulação de Richard Johnson (1999) onde está representado o circuito da produção, circulação e consumo dos produtos culturais. Aos distintos momentos desse processo, o referido autor relaciona diferentes problemáticas teóricas que revelam divisões acadêmicas e/ou disciplinares. No entanto, sua proposição parece escapar da delimitação do objeto de pesquisa centrado exclusivamente num pólo do circuito, bem como das circunscrições disciplinares. Na verdade, tal proposição não apresenta um modelo teórico acabado, mas sugere quais deveriam ser os objetos de pesquisa, pressupondo como corolário o enquadramento teórico de um determinado objeto empírico.Observo que existem outras orientações que seguem tal princípio inclusivo e que poderiam servir como guia numa trajetória de pesquisa. Esse é o caso, por exemplo, da proposição do "estudo cultural multiperspectívico", delineado por Douglas Kellner (2001) e, também, do modelo da codificação e decodificação, de Hall (2003).

O segundo aspecto, que é uma conseqüência dessa lenta reorientação de foco conceitual e que repercute nos objetos de estudo, pode ser observado no plano da pesquisa. Isto é, no deslocamento do olhar centrado nas tecnologias e na sua institucionalização, bem como nos diversos textos midiáticos, veiculados pelas mesmas, para a experiência dos sujeitos decorrentes do seu uso e apropriação de seus 
produtos $^{16}$. Não estou dizendo que a pesquisa sobre as audiências se inicia com os estudos culturais, mas que um determinado entendimento sobre essas práticas de recepção midiática é incrementado através da vinculação, mesmo que frouxa, aos estudos culturais. Embora, dentro desta concepção, a recepção não seja uma área autônoma de análise.

Se, num primeiro momento, esse deslocamento foi, em solo nacional, incentivado através das formulações de Jesús Martín-Barbero, hoje já há um reconhecimento que a nossa trajetória de pesquisa vincula-se também a um movimento maior nessa mesma direção e que este foi deflagrado pelos estudos culturais (ver, por exemplo, RONSINI, 2004). É, nesse sentido, que falo em um reposicionamento dos estudos brasileiros de recepção da virada de século, bem como em um crescente movimento de reflexão sobre seu estágio atual, impasses e futuros desafios.

O terceiro aspecto trata do interesse pela constituição das diversas identidades culturais dos sujeitos cada vez mais mediadas pelas tecnologias de comunicação - das tradicionais à nova mídia. Apesar do estágio inicial da discussão, observa-se que por ora o que ainda tem gerado mais atenção diz respeito às identidades regionais, dado, sobretudo, a intensificação do processo de globalização e mundialização da cultura e a forte circulação, no campo da comunicação, de teorias a esse respeito, incluindo aquelas que se referem ao enfraquecimento das identidades nacionais.

Mas há sinais de que as identidades de gênero, sexuais, étnicas, religiosas, juvenis, entre outras, transformem-se, em curto espaço de tempo, em um foco importante de investigação. Em especial, a problemática do gênero, da etnicidade, da cultura dos jovens e da sexualidade não são temáticas novas, mas nunca foram intensamente estudadas no campo da comunicação. Através da entrada dos estudos culturais na área, elas estão sendo teoricamente renovadas, revigorando esse viés de pesquisa.

\footnotetext{
${ }^{16}$ Mesmo que esta associação não seja percebida nem problematizada na grande maioria dos estudos brasileiros de recepção, em especial da década de 9o. Ver Escosteguy, Ana Carolina D. e Jacks, Nilda. Recepção: uma discussão conceitual. In: Capparelli, S. Sodré, M. e Squirra, S. (orgs.) A comunicação revisitada.Porto Alegre, Sulina, 2005, p. 67-84.
} 
Por último, o debate em torno das questões de ciência, tecnologia e cultura, associado ao feminismo, embora muito débil na nossa área, dado a escassa circulação da respectiva bibliografia, pode pluralizar ainda mais a reflexão sobre a tecnocultura, bem como constituir-se em mais um viés do debate epistemológico já em andamento no campo da comunicação. De outro lado, seu aporte metodológico pode fertilizar a pesquisa empírica sobre o tema, ainda, incipiente entre nós.

\section{Referências:}

AGGER, Ben. Critical Social Theories: an Introduction. Oxford,Westview, 1998.

ANG, Ien. Watching Dallas: Soap opera and the melodramatic imagination. London, Methuen, 1985.

ARONOWITZ, Stanley e MENSER, Michael. Sobre los estudios culturales, la ciência y la tecnologia. In: ARONOWITZ, Stanley; MENSER, Michael; MARTINSONS, Bárbara (orgs.) Tecnociencia y cibercultura - La interrelación entre cultura, tecnología y ciencia. Barcelona, Paidós, 1998, p.21-53.

ESCOSTEGUY, Ana Carolina D. Estudos Culturais e Recepção. Novos Olhares, São Paulo, v.2, p.44-49, 1999.

ESCOSTEGUY, Ana Carolina D. Cartografias dos estudos culturais - Uma versão latino-americana. Belo Horizonte, Autêntica Editora, 2001.

ESCOSTEGUY, Ana Carolina D. Stuart Hall: esboço de um itinerário biointelectual. Revista FAMECOS, Porto Alegre, v. 21, p. 61-71, 2003.

GUNTER, Barrie. Media Research Methods - Measuring Audiences, Reactions and impact. London, Sage, 2000.

HALL, Stuart. Estudos culturais e seu legado teórico. In: HALL, Stuart. Da diáspora Identidades e mediações sociais. Belo Horizonte, Editora UFMG, 2003, p. 199-218.

HALL, Stuart. Cultural identity and diaspora. In: Rutherford, Jonathan (org.), Identity - Community, Culture, Difference, London, Lawrence \&Wishart, 1990, 222-237. (Trad. bras.: Identidade cultural e diáspora, Revista do Patrimônio Histórico e Artístico Nacional, 24, 1996, p. 68-76.) 
HALL, Stuart. O significado dos Novos Tempos. Margem, São Paulo, n 7, p13-29, agosto 1998.

HALL, Stuart Codificação/Decodificação. In: HALL, Stuart, Da diáspora: Identidades e mediações culturais. Belo Horizonte, UFMG, 2003, p. 387-404.

HALL, Stuart Reflexões sobre o modelo de codificação/decodificação: uma entrevista com Stuart Hall. In: HALL, Stuart, Da diáspora: Identidades e mediações culturais. Belo Horizonte, UFMG, 2003, p. 353-386.

JOHNSON, Richard. O que é, afinal, estudos culturais? In SILVA, Tomas Tadeu da (org.) O que é, afinal, estudos culturais? Belo Horizonte, Autêntica, 1999.

KELLNER, Douglas. Media Culture - Cultural Studies, Identity and Politics between the Modern and the Postmodern. London/New York: Routledge, 1995. (Trad. bras.: A cultura da mídia - estudos culturais:identidade e política entre o moderno e o pós-moderno. Bauru: EDUSC, 2001.)

KEMBER, Sarah. Feminismo, tecnología y representación. In: CURRAN, James; MORLEY, David; WALKERDINE, Valerie (orgs.). Estúdios culturales y comunicación - Análisis, producción y consumo cultural de las políticas de identidad y el posmodernismo. Barcelona: Paidós, 1998, p. 347-373.

LEITE, Sidney Ferreira. Reflexões sobre comunicação e sociedade: as contribuições de Douglas Kellner. In: e-compós, edição 1. Disponível em: http://www.compos.org.br/e-compos, edição 1. Acesso em dezembro de 2004.

MORLEY, David. The Nationwide audience. London: British Film Institute, 1980.

MORLEY, David. Family television: Cultural power and domestic leisure. London: Comedia, 1986.

PLANT, Sandie. On the matrix: cyberfeminist simulations. In: THORNHAM, Sue; MARRIS, Paul (orgs.). Media Studies - A Reader. Nova York: New York University Press, 2000, p. 835-848.

PROCTER, James. Stuart Hall. London, Routledge, 2004.

RADWAY, Janice. Reading the romance: Women, patriarchy and popular literature. Chapel Hill/ London, University of North Carolina Press, 1984.

ROJEK, Chris. Stuart Hall. Cambridge, Polity, 2003.

RONSINI, Veneza M. Entre a capela e a caixa de abelhas - identidade cultural entre gringos e gaúchos. Porto Alegre, EDIPUCRS, 2004.

RÜDIGER, Francisco. Programa de pesquisa: premissas e discurso do método. In: RÜDIGER, Francisco. Theodor Adorno e a crítica à indústria cultural comunicação e teoria crítica da sociedade. Porto Alegre, EDIPUCRS, $3^{\text {a }}$ ed, 2004, p.237-267.

RÜDIGER, Francisco. Ciência social crítica e pesquisa em comunicação - Trajetória histórica e elementos de epistemologia. São Leopoldo, Editora Unisinos, 2002. 